\title{
Theoretical Model and Development of IoT based Digital Agricultural System
}

\author{
Asmita, Isteyak Ansari, Pratik More, Amit Patwardhan, Yashodhan Mandke, Rabinder Henry
}

\begin{abstract}
The proposed work describes the basic idea and a theoretical framework for design and development of internet of things and machine learning based digital agricultural system. This work includes statistical review of existing issues faced by farmers in India. Based on this analysis, an embedded system platform that includes soil characterization module, environment monitoring module and drone delivery system is being developed.
\end{abstract}

Keywords- Agriculture, Cloud, Drone, IoT, Machine learning, Sensors

\section{Introduction}

India has been an agrarian society for the last 5000 years [1]. After independence in 1947, under the guidance of M.S. Swaminathan, the "Green Revolution" was initiated; which perpetually elevated millions of Indian out of poverty [2].

Eventually in last couple of decades, India has evolved as a major player in agricultural production and export [3]. But still, there is large population of India that follows century old agricultural techniques and machinery. Indian agriculture began by $9000 \mathrm{BCE}$ as a result of early domestication of plants and animals [4]. It started with animal-drawn ploughing which continued for centuries. Later when the British came to India they started introducing steam engines. This was followed by tractors which are in use till date. This move continued to expand mechanization of tilling, sowing, and harvesting and usage of modern farm equipment in the Indian market. The improved technology utilization and the introduction of high yielding varieties of seeds and fertilizers aided in Green Revolution [10] which made India selfsufficient in farm production in late 60s. Still there are cases of farmers' suicides across the country. Unseasonal climatic conditions, low productivity, physically draining manual work and fluctuation in market price of crop are the major reasons for this ill fate of farmers [5]. Today, various works are being done to digitalize agriculture with drone technology [11]. Solar based automated fertigation control system using Zigbee modules [6], Microcontroller based drip irrigation system using IoT(Internet of Things ) [7], Digital soil testing [8], and Food processing industry[9] are some of the work that have been utilizing development in sensor and embedded technology.

Asmita, Isteyak Ansari, Pratik More

E \& TC Department, International Institute of Information Technology Pune, India

Amit Patwardhan, Yashodhan Mandke, Rabinder Henry

Pralhad.P.Chhabria Research Center

Pune, India
This provided a base to design and integrate novel ideas of digitalizing agriculture on the pretext that it would mitigate farmers' suicides. Based on survey conducted, an IoT and machine learning based theoretical design of digital system is proposed in this paper to solve some of the farming related issues of farmers. The main aim is to provide a solution that is portable and ensure higher crop yield. This overcomes the problem of installation of permanent sensing modules. Section 2 shows the survey conducted and results inferred based on collected data. This survey is based on a sample size of 20 farmers. Section 3 shows the proposed solution and also current status of the design.

\section{Survey Summary}

\section{A. Survey}

The survey was conducted in a locality in Mulshi taluk in Pune district in the state of Maharashtra, India (latitude 18.597059 and longitude 73.718823 ). The actual village is roughly $30 \mathrm{Kms}$ away from city of Pune. The sample size is evaluated based on definitive set of quantitative and qualitative variables. This data includes information about the area of the cultivated farm size, type of crops grown, water requirement, effect of weather change, soil testing, market value of crop, machinery used, type of irrigation, crop rotation, crop failure and labour related issues faced by the farmer in that particular locality. Figure 1 represents the various farming related issues faced by farmers and their conditions.

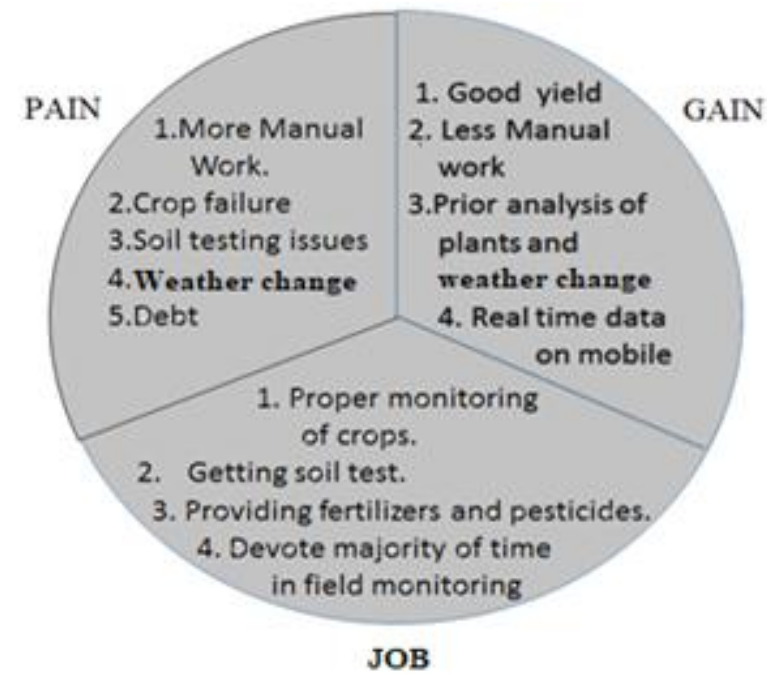

Figure1. Farmers' View Point 


\section{B. Analysis}

Figure 2 shows the statistical analysis. It is the average rating of various parameters given by farmers based on recorded interactions. It shows how a particular parameter affects farmers and the extent to which it plays a role.

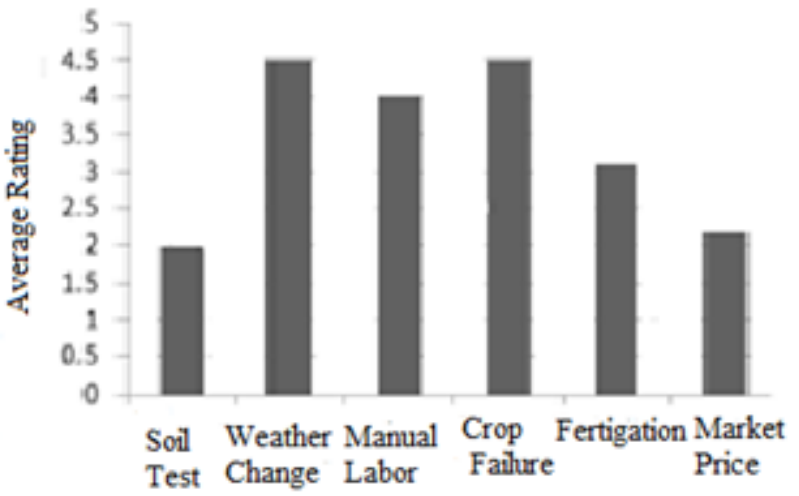

Parameters

Figure 2. Statistical Analysis of Problems

Multiple field visits were done to interact with farmers. This was carried out to get first-hand information about the current scenario of farming related issues. The statistical analysis is scaled between 1 to 5. As per the survey, agriculture requires a lot of physical work and proper monitoring. There is a great risk of crop failure due to unseasonal weather condition and improper monitoring. This statistical analysis shows the following major problems faced in agriculture specific to geographical location - 1) Unseasonal weather condition 2) Crop failure 3) Manual labour 4) Poor crop yield 5) Low market price of crop. This paper theoretically describes about the solution that could reduce the risk of crop failure to ensure higher productivity and at the same time gives a brief description of the development of the design. The proposed method is explained in section 3. The proposed method is explained in section 3 .

\section{Proposed Solution}

The proposed design includes solution based on the different cultivatable areas of the farms.

In this paper portable solution is presented that could be suitable for both small and large farm area. It has been experimented to overcome the drawback of portability associated with wireless sensor network.

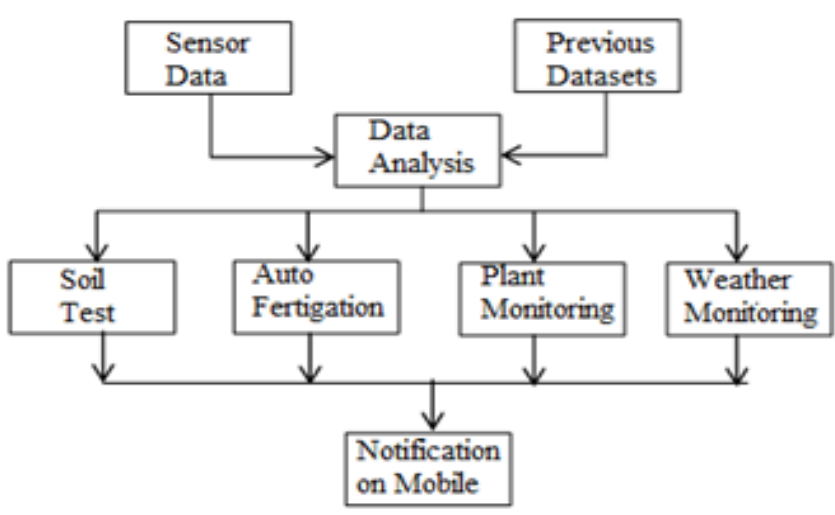

Figure 3. Block Diagram

Figure 3 shows the block diagram. The proposed design uses concept of machine learning, IoT and cloud to make system portable and give efficient analysis through smart device for small fields [15]. The use of hyperspectral imaging makes it possible to accurately analyse plant health

\section{A. Design for Small / Indoor farms}

Figure 4 shows the proposed design for small farming (less than 2 hectares) and indoor farming like Green House farming and plant factory of Japan [12].

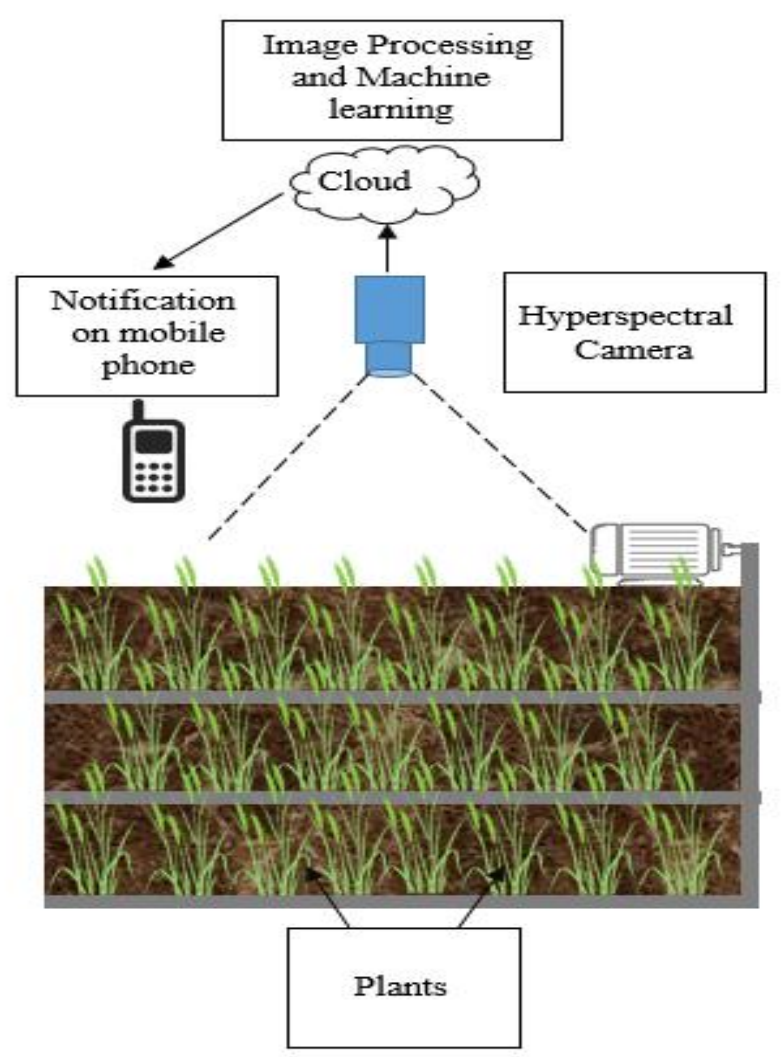

Figure 4. Proposed Design for Small Farms 
The system design consists of hyperspectral camera deployed in field that measures and records the spectral information of light reflected from plants. The range of hyperspectral sensor varies from visible/near infrared region (380nm-1000nm) to long spectral region (8-12 microns) [16]. The spectral analysis identifies the problems of weed, plant disease and NPK deficiency. The reflective properties of the plants are affected due to multiple agricultural stresses. The design module for indoor farming consists of white light source like LED bulbs. Healthy and affected crops reflect the light differently. Hyperspectral sensor detects small changes in the physiology of the plants.

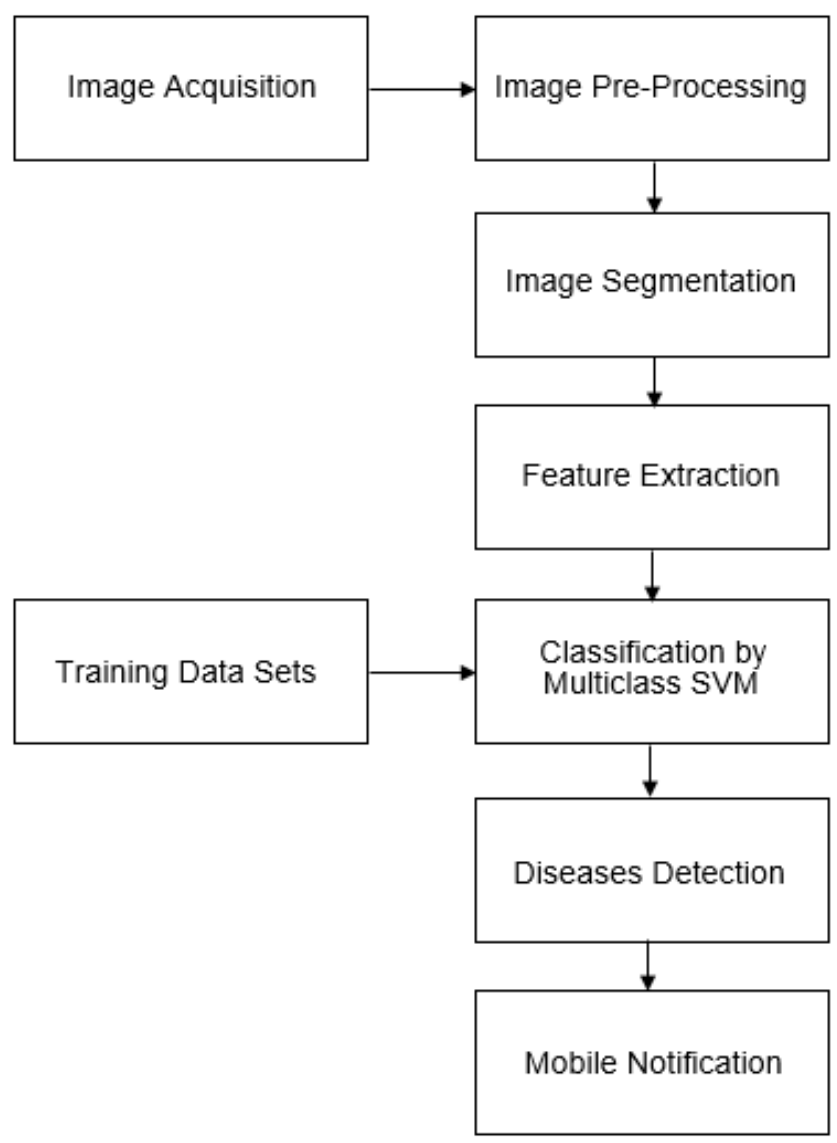

Figure 5. Flowchart of Proposed Solution

Figure 5 shows the flowchart of proposed solution. Image processing algorithms are used to pre-process the images captured by hyperspectral camera. In order to acquire better result, different factors are considered which include resizing of image, noise removal and image enhancement [17]. The proposed solution uses bilateral filter technique for noise removal.

The pre-processed image is send to cloud through IoT. Over Cloud, image segmentation is done to extract the region of interest by masking out the background. The required features like, spectral reflectance, colour, shape, texture are extracted from image using Open Source Computer Vision (Open CV) in Python. These extracted datasets are provided for supervised learning using multiclass Support Vector Machine (SVM) algorithm. The algorithm comprise of training sets and testing datasets. The datasets consist of features extracted from captured image. This provides the system with the intelligence to identify any affected area of farm, the area that requires pesticides and fertilizers, the weather condition and proper timing of harvesting and sowing to get better crop yield. These information and notification are sent to customers through mobile applications. Having received the notification customers can trigger the required action like, water pump control. To achieve higher agricultural productivity yields, the weeds need to be identified and managed effectively. Traditionally used chemicals for managing weeds cause issues with economic losses, environment pollution, and unsafe foods. To deal with such issues chemicals should be used precisely and applied accurately according to the requirements. Therefore, detecting and analysing the information of spraying targets is a critical process. The availability of prior information of affected area helps the farmers to take early remedy. This would save the entire field from being damaged.

\section{B. Design for Large Farms}

In case of large fields, drone technology is used to collect data through powerful imaging sensors.

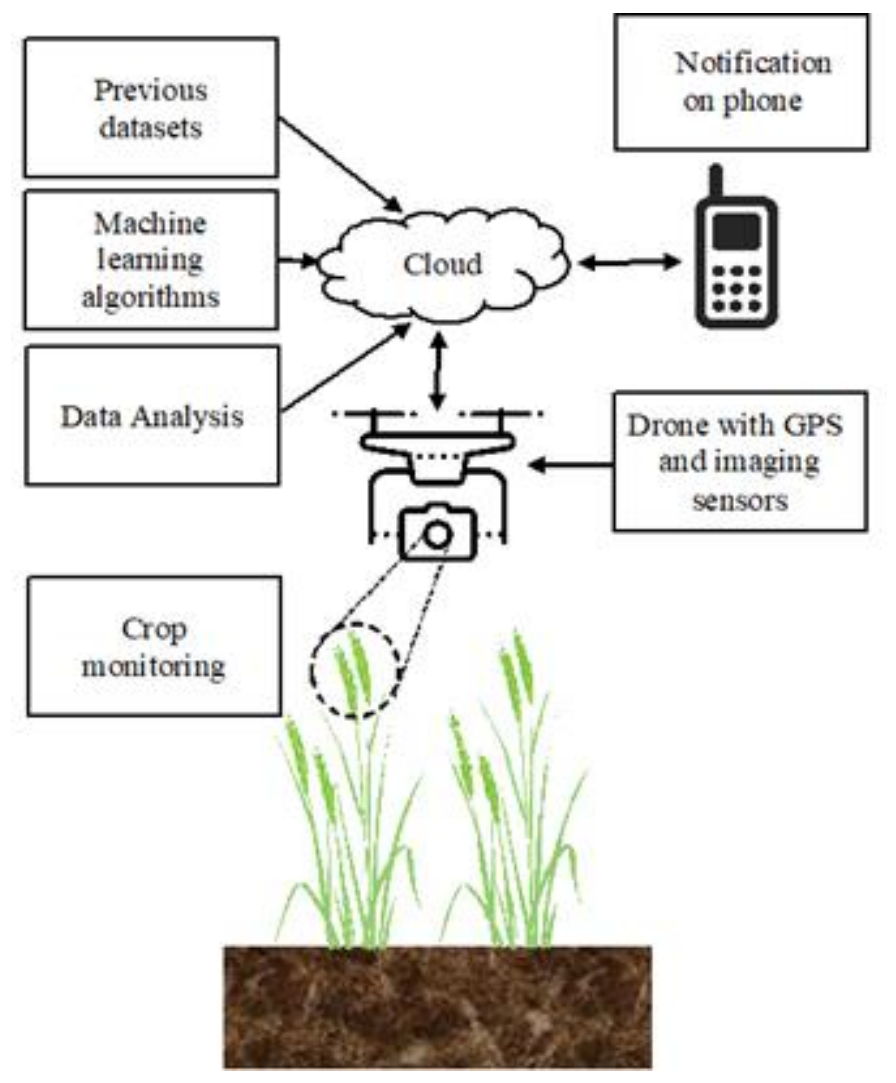

Figure 6. Design for Large Farms

Figure 6 shows the proposed design model for large farm. Similar to small farm model, remote sensing technique proposed here needs some initial data input sets for pre- 
processing. These pre-processed data is used in SVM machine learning algorithm to make a system model. This system receives the current set of data using IoT. The intelligent decision taken is then provided to farmers which can be accessed from anywhere. The sensors used include hyperspectral imaging for plant health monitoring [13]. The spectral properties of plants are useful to remotely monitor the contents of the nutrients [14]. The large amount of data generated is intelligently used to predict the ideal type of crop that farmers should select to increase crop productivity. Figure 7 shows the prototype demo model of the drone.

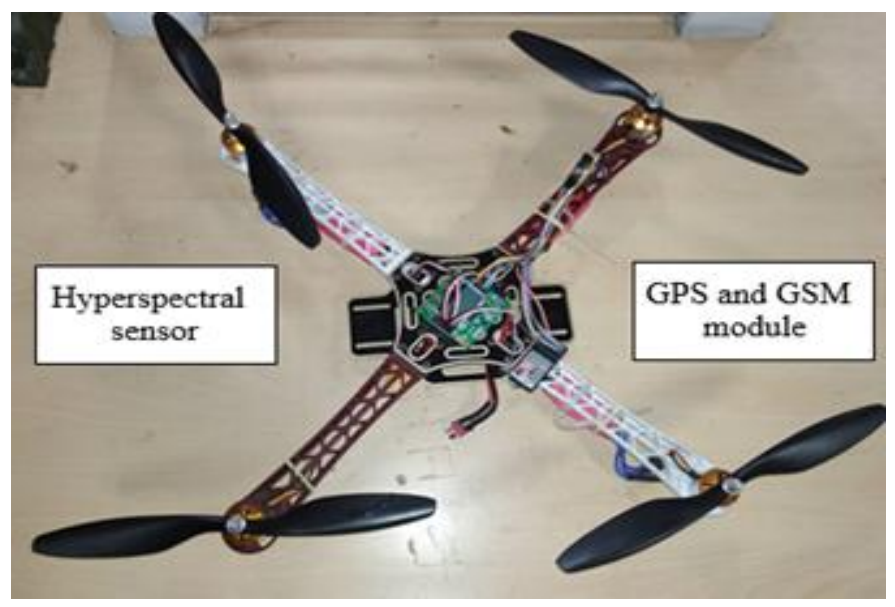

Figure 7. Prototype model of Drone

\section{Future Scope}

Applying IoT and data analysis with machine learning into agriculture could revolutionize smart agriculture. There will soon be "Internet of Agriculture". Even a minor disease in one small section of field could destroy the complete farm. The proposed model could intimate farmers regarding plants disease in advance. This could be done by sending notification on an app that would show the location of field through mapping and also by notifying the proper remedies. This could also be extended to auto plantation, auto fertilizing and pesticides spraying. User can just draw the pattern on the app and accordingly the plantation would be done. The uncertainty in climatic change causes great loss. The proposed model would notify the climatic change well in advance and accordingly, harvesting or plantation could be done. This would reduce risk of crop failure. This model could be applied to emerging indoor farming as well.

\section{v. Conclusion}

The proposed model has the potential to bring smart green revolution using the concept of IoT and machine learning. This system ensures better crop yield and better returns from the market. It reduces wastage of water and fertilizers. Thus smarter and efficient decision could be taken. Hence, chances of crop failure could be reduced to a great extent. The development of each module is being communicated to different journals.

\section{References}

[1] Barth, F.2001. Features of Person and Society under Agrarianism.

[2] Wikipedia, https://en.m.wikipedia.org/wiki/M._S._Swaminathan, M.S.Swaminathan [Accessed: September 21, 2017]

[3] Wikipedia, https://e.m.wikipedia.orgg/wiki/Agriculture_in_India Agriculture in India. [Accessed: September 21, 2017]

[4] Wikipedia,https://e.m.wikipedia.orgg/wiki/History_of_agriculture_in_th e_Indian_subcontinent, History of agriculture in the Indian subcontinent [Accessed: October 14, 2017]

[5] Wikipedia, https://en.wikipedia.org/wiki/Farmers\%27_suicides_in_India, Farmers' suicide in India. [Accessed: October 21, 2017]

[6] S. Venkatraman, L. Devandra Kumar, E. Anish, V.X. Abinesh and M. Anto Bennet, "Solar powered automated fertigation control system for terrace farming using zigbee". Middle-East Journal of Scientific Research 24 (Techniques and Algorithms in Emerging Technologies): 401-407, 2016

[7] G.Parameswaran, K.Sivaprasath, "Arduino based drip irrigation system using internet of things". IJESC

[8] Balwant Singh and Viacheslav I. Adamchuk, "Digital (on- the- go) soil testing advances".

[9] Suiqiong Li, Aleksandr Simonian, and Bryan A. Chin, "Sensors for Agriculture and the Food Industry".

[10] A. K. Sharma, Seema Wahab, Rashmi Srivastava, "Agricultural diversification".

[11] Alfonso Torres-Rua, "Drones in Agriculture: An overview of current capabilities and future directions".

[12] Toyoki Kozai, "Plant Factory in Japan - current situation and perspectives".

[13] D. Ramakrishnan* and Rishikesh Bharti, "Hyperspectral remote sensing and geological applications".

[14] P.C. Scharf, J.P. Schmidt, N.R. Kitchen, K.A. Sudduth, S.Y. Hong, J.A. Lory, and J.G. Davis, "Remote sensing for nitrogen management"

[15] Akash Raj N, Balaji Srinivasan, Deepit Abhishek D, Sarath Jeyavanth J, Vinith Kannan A, "IoT based Agro Automation System using Machine Learning Algorithms". International Journal of Innovative Research in Science, Engineering and Technology (An ISO 3297: 2007 Certified Organization) Vol. 5, Issue 11, November 2016.

[16] Headwall, "Hyperspectral imaging for remote sensing appplications".

[17] Zarreen Naowal Reza, Faiza Nuzhat, Nuzhat Ashraf Mahsa, Md. Haider Ali, "Detecting Jute Plant Disease Using Image Processing and Machine Learning". Electrical Engineering and Information Communication Technology (ICEEICT), 2016 3rd International Conference.

About Author (s):

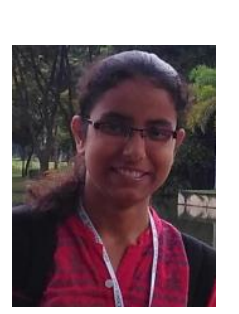

Asmita

E \& TC Department, International Institute of Information Technology Pune, India 
Proc. of the Eighth International Conference On Advances in Computing, Electronics and Electrical Technology - CEET 2018 Copyright ( $\odot$ Institute of Research Engineers and Doctors. All rights reserved.

ISBN: 978-1-63248-144-3 doi: 10.15224/ 978-1-63248-144-3-07

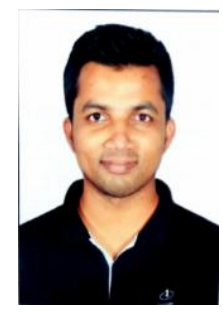

Isteyak Ansari

E \& TC Department, International Institute of Information Technology

Pune, India
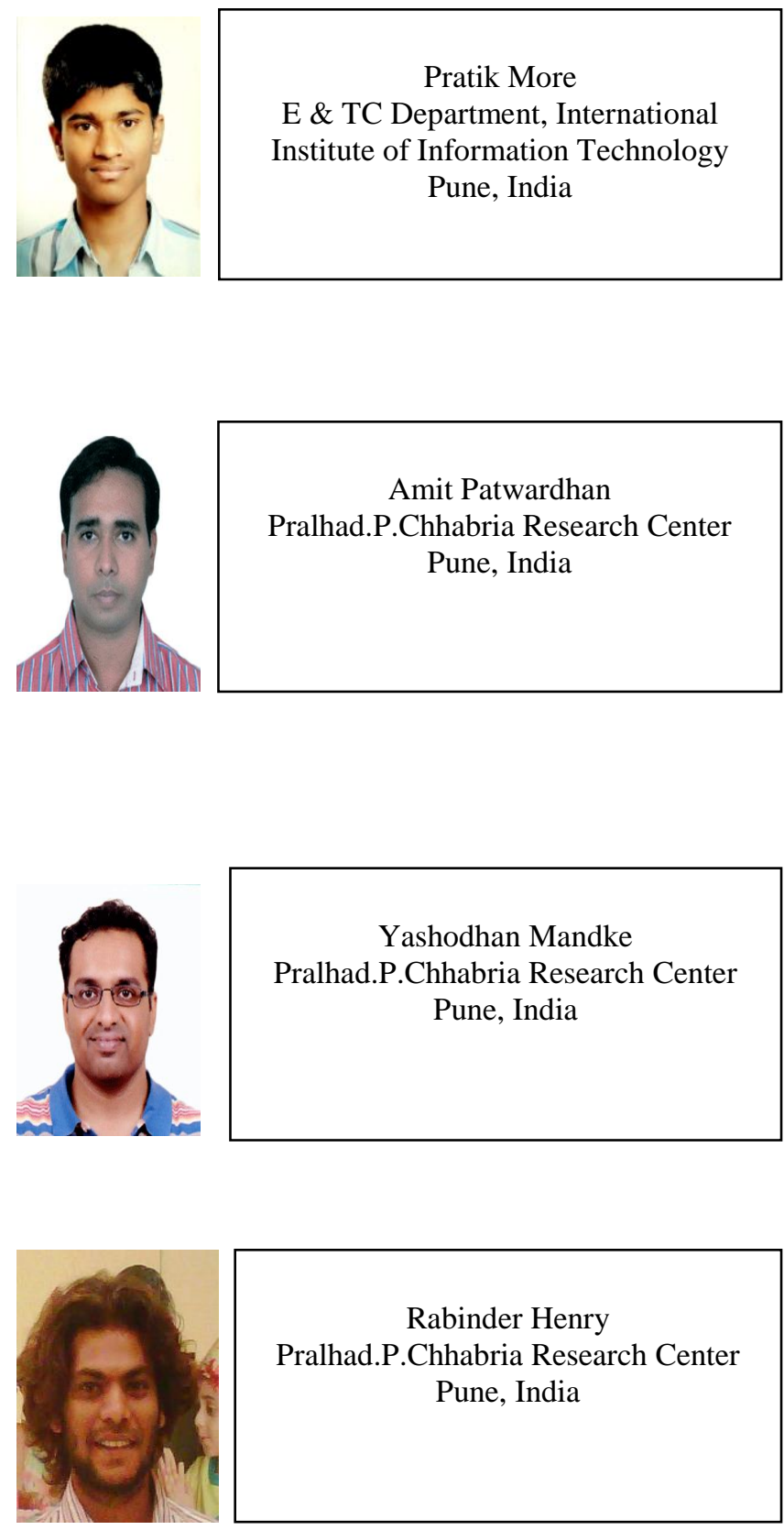

Rabinder Henry

Pralhad.P.Chhabria Research Center

Pune, India 